\title{
Clinical Spectrum of Infertile Couple: a Retrospective Study at Teaching Hospital
}

\author{
Hima Rijal', Suvana Maskey ${ }^{1}$ \\ ${ }^{1}$ Department of Obstetrics and Gynaecology, Institute of Medicine, Tribhuvan University Teaching Hospital, Kathmandu, Nepal
}

\section{ABSTRACT}

Introduction: Infertility has been rising steeply as the prime health issue among women around the world these days. This study aims to investigate the causes, hormonal profile, and clinical spectrum of infertility.

Materials and Methods: This is a descriptive cross-sectional study conducted throughout a oneyear duration in an infertility clinic. The couples meeting the inclusion criteria were included and a pre-formed proforma was used to collect the data regarding history, examination, and investigations.

Results: A total of 118 infertile couples were analyzed. The mean age of the females was $28.3 \pm 4.5$ years. There were $72.1 \%$ cases of primary infertility and $27.9 \%$ of secondary infertility. Regarding obesity status, $35.5 \%$ were overweight and $15.2 \%$ were obese. Thirty-one (26.2\%) males were smokers, $41(34.7 \%)$ used to consume alcohol, and $14(11.8 \%)$ had a habit of chewing tobacco. Among the different findings of semen analysis, $21.1 \%$ asthenozoospermia, $9.3 \%$ oligoasthenozospermia, $7.6 \%$ oligospermia, $1.6 \%$ azoospermia. Female factor accounted for $45.3 \%$, the malefactor for $28 \%$ and in $19.3 \%$ the definite factor was not determined. The ovulatory disorder was diagnosed in $38.6 \%$ of females and hysterosalpingography revealed that around $10 \%$ had a unilateral block and $1.7 \%$ had a bilateral block.

Conclusions: Infertility is becoming a global issue affecting a significant number of young couples. About forty-six percent were female aging more than thirty years. The female factor for infertility was more common than the male factor among which ovulatory disorder was the commonest one. Asthenozoospermiawas the commonest abnormal finding on semen analysis in a male partner.

\section{Correspondence:}

Dr. Himal Rijal, MD

Department of Obstetrics and Gynaecology,

Institute of Medicine, Maharajgunj, Kathmandu/Nepal ORCID ID: 0000-0002-0059-7754

Email: rizhima@hotmail.com

Submitted: $5^{\text {th }}$ November 2020 Accepted: 24 $4^{\text {th }}$ December 2020

Source of Support: None Conflict of Interest: None

Citation: Rijal H. Maskey M. Clinical spectrum of infertile couple, a retrospective study at teaching hospital. NMJ 2020;3(2):375-8. DOI 10.3126/nmj. v3i2.35117

Keywords: Anovulation; Asthenozoospermia; Infertility; Obesity

\section{INTRODUCTION}

Infertility has become a global challenge with increasing trends each year. Infertility implies the inability of a sexually active, non-contracepting couple to achieve pregnancy in one year. Normally it is observed that $50 \%$ of couples conceive within 3 months of regular unprotected intercourse, $75 \%$ in six months, and $80-85 \%$ conceive within a year. ${ }^{1}$ Primary Infertility is defined as when a couple fails to conceive, after a minimum of one year. Secondary Infertility is described in couples who have previously been pregnant at least once but had not been able to achieve another pregnancy. Infertility can result due to male factors, female factors and in many couples both male and female factors are present. In the case of a single factor, the fertile partner may compensate for a less fertile partner. Thus infertility usually manifests if both partners are subfertile. ${ }^{2}$ These couples may seek assisted reproduction which includes all the methods used for fertilization. $^{3}$ 
The prevalence of infertility varies across the world and is estimated to affect 8 to $12 \%$ of couples worldwide. ${ }^{4}$ Underlying these numbers exists a core group of couples, estimated to be 3 to $5 \%$, who are infertile due to unknown or unpreventable conditions. The prevalence of infertility above this level suggests preventable or treatable causes. ${ }^{5}$

Factors like genetic or endocrine abnormalities, infectious or environmental agents, and behavioral factors may influence human fertility. Age factor has a pivotal role in infertility. Recent trends toward postponing age at first pregnancy have highlighted the natural limits of fertility and accelerated the development and use of medical technology to overcome such limits. It has also been observed that the causes are related to geographical differences as well. In Western countries, age factor whereas in Africa sexually transmitted diseases (STI) are considered as the common factor for infertility. ${ }^{6}$

Hormonal disturbances have been contemplated as one of the prime factors for barrenness so far. Different levels of the hormone at different phases of menstruation give clues about the primary dysfunction in the infertile women such as an increase in folliclestimulating hormone (FSH) may indicate decreased ovarian reserve. As a consequence, there is a lower chance for her to conceive. ${ }^{7}$ Leutinizing hormone (LH) works in conjunction with FSH for maintaining the menstrual cycle and ovulation. Similarly, other hormones such as estradiol, progesterone, androgens, prolactin, thyroid hormone, each have an important role in female reproductive functions. Measurement of these hormones is an effective tool for the diagnosis and management of infertility. ${ }^{8}$ In addition, semen analysis, hysterosalpingogram, ultrasonological examination assists for identification and management as well. This study gives a spectrum of the socio-demographic profile and clinical status of infertile couple proportions of different factors of infertility and the different causes of infertility at the tertiary centre of the country.

\section{MATERIALS AND METHODS}

This is a descriptive cross-sectional study conducted in the Infertility Department of Gynaecology \& Obstetrics from 14th April 2019 to $13^{\text {th }}$ April 2020.). Ethical approval from the Institutional Review Committee of IOM and Research Department was taken before starting the study. A couple attending infertility clinics were included in the study. Data were collected from the record book. Incomplete information on record regarding history, clinical examination, or investigation were excluded. After proper history taking and examination of couple investigations were sent. LH, FSH, Estradiol, and Testosterone were sent on day two of the menstrual cycle in addition to baseline investigations including thyroid function test and prolactin. Hystero-salphingography was performed on the sixth to the eleventh day of the menstrual cycle. A baseline ultrasound was done. Semen analysis of the male partner was performed after the third to sixth days of abstinence. The data were collected and analyzed by using SPSS version 20 .

\section{RESULTS}

A total of 118 infertile couples presented during the study period and their variables were analyzed. The mean age of the females was $28.3 \pm 4.5$ ranging from 20 to 38 years. 69 (58.47\%) were of
20-29 years of age, of which 54/69 had primary infertility and $15 / 69$ had secondary infertility. Similarly, 49(41.53\%) were of $30-39$ years age group of which $31 / 49$ had primary infertility and $18 / 49$ had secondary infertility.

There were $72.1 \% \quad(n=85)$ cases of primary infertility and $27.9 \%(n=33)$ of secondary infertility. The mean age of females with primary infertility was $27.65 \pm 4.80$ years and secondary infertility was $30.21 \pm 3.37$ yrs. Seventy patients $(58.8 \%)$ had a regular menstruation cycle, whereas 48 patients $(40.3 \%)$ had an irregular menstrual cycle. Regarding the obesity status, $4.2 \%$ $(\mathrm{n}=5)$ were underweight, $45.7 \%(\mathrm{n}=54)$ had normal body weight, $35.5 \%(\mathrm{n}=42)$ were overweight and $15.2 \%(\mathrm{n}=18)$ were obese (fig. $1)$.

Regarding the educational status of male, $13.2 \%(\mathrm{n}=18)$ did not complete primary school, $25.4 \%(\mathrm{n}=30)$ completed primary school, $23.7 \%(\mathrm{n}=28)$ completed high school and $35.5 \%(\mathrm{n}=42)$ university graduates .On the other hand among female $7.6 \%(n=9)$ illiterate, $35.5 \%(n=42)$ not completed primary school, $16.9 \%(\mathrm{n}=20)$ completed primary school, $17.7 \%(\mathrm{n}=21)$ completed high school and $22 \%(n=26)$ were university graduates.

Regarding the occupation of the male partner, $26.27 \%$ were jobholders, $18.61 \%$ were businessmen, $8.47 \%$ farmers, $5.9 \%$ teachers, $5.08 \%$ were cooks, $4.2 \%$ were a driver and $2.5 \%$ were welder. However, others (contractor, policeman, engineer, doctor, waiter) accounted for $35.59 \%$. The majority of female (55\%) partners were housewives, $16.9 \%$ were jobholders and the rest were from a different job (student, tailor, teacher, business, etc) accounting for 27.9 percent. Thirty-one (26.2\%) males were smokers, 41 (34.7\%) used to consume alcohol, and 14 (11.8\%) had a habit of chewing tobacco.

Among the different factors of infertility, the female factor accounted for $45.3 \%$, the malefactor for $28.7 \%$ and in $19.3 \%$ the definite factor was unexplained. More than one factor was observed in $6.7 \%$ of cases (fig. 2).

Among the different findings of semen analysis $21.1 \%$ asthenozoospermia, $\quad 9.3 \%$ oligoasthenozospermia, $\quad 7.6 \%$ oligospermia, $1.6 \%$ azoospermia. Regarding two cases of azoospermia, one had bilateral small testes and the other case was Klinefelter syndrome

Among female factors, the ovulatory disorder was diagnosed in $38.6 \%$, tubal factors in $4.2 \%$, fibroid uterus is $1.7 \%$, and endometriosis in $0.8 \%$. Abnormality in ovulation is divided according to the gonadotrophic status of the individual. These categories are important in deciding the treatment as well as in counselling. This study showed the WHO group II ovulatory disorder, PCOD $9.2 \%$, and thyroid disorder in $8.4 \%$. Hyperprolactinemia was seen in $21 \%$. Regarding ultrasonographical findings, $72.3 \%(n=83)$ had normal finding, $9.2 \%(n=11)$ had polycystic ovaries, and other findings in a smaller number of patients as shown in table 1 
Table 1: Ultrasound findings of female partners

\begin{tabular}{ll}
\hline Ultrasound findings & Percentage (number) \\
\hline Normal & $68.6 \%(\mathrm{n}=81)$ \\
\hline Polycystic ovaries & $9.2 \%(\mathrm{n}-11)$ \\
\hline Uterine fibroid & $5.9 \%(\mathrm{n}=7)$ \\
\hline Endometiotic cysts & $5.9 \%(\mathrm{n}=7)$ \\
\hline Ovarian cyst & $3.3 \%(\mathrm{n}=4)$ \\
\hline Hydrosalphinx & $1.7 \%(\mathrm{n}=2)$ \\
\hline Endometrial /cervical polyp & $1.7 \%(\mathrm{n}=2)$ \\
\hline Adenomysis & $1.7 \%(\mathrm{n}=2)$ \\
\hline uterine( mullarian)anomaly & $0.8 \%(\mathrm{n}=1)$ \\
\hline Endomertrial hyperplasia & $0.8 \%(\mathrm{n}=1)$ \\
\hline
\end{tabular}

Regarding hysterosalpingography (HSG) finding , 88.2\%(n=105) had bilateral spillage of dye in hysterosalphingogram, $10.1 \%(\mathrm{n}=12)$ had unilateral block and 1.7\%(n=2) had bilateral block

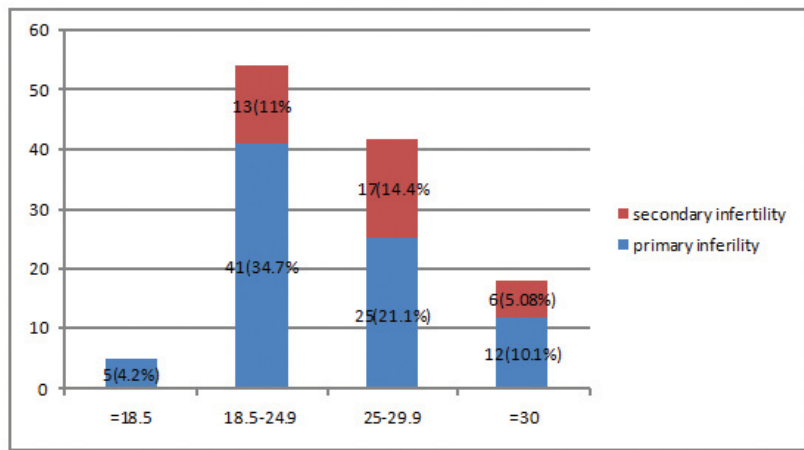

Figure 1: Distribution of female partner according to BMI

Percentage of differtent factor of infetility

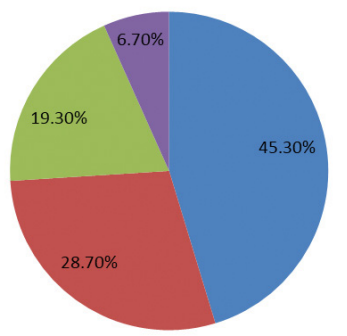

- female factor

- male factor

- unexplained

more than one factor

Figure 2: Distribution of different factors of infertility

\section{DISCUSSION}

The literature describes infertility as a multi-dimensional health issue resulting from a complex interplay between various factors. These include abnormal state of reproductive organs as well as modern lifestyle-related issues such as the age of marriage, age of having children, stress, and unconducive legal framework for assistant reproduction, etc. The prevalence of infertility varies across the world ranging between $3.5 \%-22 \% 9$, possibly due to the recruitment process of the study population, infertility definitions, and method of estimation. Advances in the diagnosis, treatment, and prevention of infertility in the past decades have led to considerable changes in the worldwide prevalence of infertility. ${ }^{9}$ The proportion of primary infertility in our centre is higher $(73 \%)$ which in concordance with Shrivastava VR et al. ${ }^{10}$ On the contrary, secondary infertility was proportionately high in places where the prevalence of STI is high. ${ }^{11-13}$

About forty-six percent were females aging more than thirty years signifying the inclining subfertility with age. Abnormal body mass index (BMI) causes infertility due to ovulatory dysfunction and insulin resistance. The underweight female had inappropriate gonadotrophin-releasing hormone $(\mathrm{GnRH})$ release leading to menstrual disturbance and infertility. It has been seen that obese women with a normal menstrual cycle also have less chance of becoming pregnant. ${ }^{14}$ This study showed $50 \%$ of women were either overweight or obese. Zafar M. showed that women with high BMI (BMI 30 and above) were more than four times and women with BMI 25 to 29.9 were more than one times sub-fertile compared to normal (BMI 20.0-22.4). ${ }^{14}$ There are consistent evidence showing that menstrual disorder is associated with obesity leading to subfertility. ${ }^{14}$

Regarding socio-demographic data of this study, $55.2 \%$ of women were housewife and about $45.8 \%$ were working women similar to the result shown by Mokhtar et $\mathrm{al}^{15}$ however the findings disagree with the study done by Ali et al. ${ }^{16}$ where all the female were housewife, such differences may be imputed to the variations of the population community and sample taken.

In the present survey, the female factor infertility accounted for the highest rate of infertility $(45.3 \%)$, which matches the results of studies conducted in Iran. ${ }^{9,17}$ Safarinejad MR found male factor as the primary cause of infertility. ${ }^{18}$ This discrepancy may be due to different study designs, characteristics of the participants, and sample size. In most studies, the frequency of male factor, female factor, both of them, and other unknown cause were 20$40 \%, 30-35 \%, 35 \%$, and 5-15\%, respectively. ${ }^{9} 17$ Infertile couples usually report more than one reason for their infertility and there are fewer single causes. ${ }^{17}$

Asthenozoospermia was the commonest findings on semen analysis which was comparable to the study done by Makhadumsab M. Toragall et al. ${ }^{14}$ However the findings contradict results by Samal $\mathrm{S}$ et al. ${ }^{15}$ where the higher percentage of oligospermia reported as the maximum number of males was older age group (above 35 yrs). Makhadumsab M. Toragall et al. noticed asthenozoospermia more in laborers and males with multiple addictions.

This study showed $72.8 \%$ of the male had some type of addiction. Addictions like smoking, alcohol, and chewing tobacco, or the combination of these had an inimical effect on spermatogenesis. However, a larger study needed to be done to find the association between addiction and semen abnormalities. The high concentration of free radicals released due to smoking cause sperm damage ${ }^{14}$ where as excessive consumption of alcohol results in lowering testosterone levels, FSH, LH and raising estrogen levels, which reduce sperm production, causes shrinkage of testes and can lead to impotence or infertility. ${ }^{14}$ Makhadumsab M. Toragall compared semen parameters such as sperm count and motility with respect to lifestyle addictions revealed statistically significant result $(\mathrm{p}<0.05)$ when compared with participants having no addictions. ${ }^{8,16}$

Among the female factors of infertility, ovulatory disorder(38.6\%) was the commonest contrary to the findings of Mital et al. ${ }^{19}$ where tubal factor was the leading female factor to cause infertility. 
However, Kazemijaliseh $\mathrm{H}$. et al. also had shown ovulatory disorder $(39.7 \%)$ followed by malefactors $(29.1 \%)$. Older ages of marriage for women and tendencies of delayed childbearing among couples could be the factor for increasing ovulatory disorder nowadays. ${ }^{6}$ Hyperprolactinaemia (21\%) being the commonest endocrinopathies in isolation contrary to reports byPalihawadana TS, ${ }^{6}$ where PCOS was the commonest among the ovulatory dysfunction.

This study had abnormal HCG findings in minors (11.3\%) as compared to Shrivastava VR et al $(29.0 \%) .{ }^{10} \mathrm{HSG}$ abnormalities were multiples high in studies of Ramzan R et al ${ }^{20}$ Bukar et al. ${ }^{21}$ Malwadde EK et al. ${ }^{22}$ with $61.9 \%, 70.6 \%, 83.4 \%$, respectively, which were more associated with secondary infertility. Heaps of normal HSG with primary infertility in the current study advocate the cause may be non-structural or due to male infertility factor.

\section{CONCLUSIONS}

Infertility is becoming a global issue affecting a significant number of young couples. About forty-six percent were females aging more than thirty years. Female factor (45.6\%) for infertility was more common than male factor among which ovulatory disorder (38.6\%) was the commonest one. Older ages of marriage for women and tendencies of delayed childbearing among couples could be the factor for increasing anovulation. Asthenozoospermia $(21.1 \%)$ was the commonest abnormal finding on semen analysis in male partners and $72 \%$ of the male had some type of addiction. However, a larger study is needed to find the association between the addiction and semen abnormalities

\section{REFERENCES}

1) Padubidri VG, Daftary SN. The pathology of conception. Howkins\& Bourne Shaw's textbook of gynaecology. Elsevier, New Delhi 15. 2011. pp197-220.

2. Cooper TG, Noonan E, von Eckardstein S, Auger J, Baker HW, Behre HM, et al. World Health Organization reference values for human semen characteristics. Hum Reprod Update. 2010;16:231-45. $\underline{\text { Crossref }}$

3) OmbeletW,Cooke I,Dyer S,Serour G,DevroeyP.Infertility and the provision of infertility medical services in developing countries. Hum Reprod Update. 2008;14(6):605-21. Crossref

4) Kumar D. Prevalence of female infertility and its socio-economic factors in tribal communities of central India.Rural and Remote Health. 2007;7: 456. Crossref

5) Adamson PC,Krupp K,Freeman AH, Klausner JD, Reingold AL, Madhivanan P. Prevalence \& correlates of primary infertility among young women in Mysore, India. Indian J Med Res. 2011;134:440-6. Website

6) Roupa Z, Polikandrioti M, Sotiropoulou P, Faros E, Koulouri A, Wozniak G, Gourni M.Causes of infertility in women at reproductive age. Health Science Journal.2009; 3(2),80-7. Website

7. Lee, D.S, Ryoo, N.Y, Lee, S. H, Kim S et al. Basal luteinizing hormone and follicular stimulating hormone: is it sufficient for the diagnosis of precocious puberty in girls.Ann Pediatr Endocrinol Metab,2013; 18:196-201. Crossref

8) Digban KA, Enitan SS, Jemikalajah JD, Adama S.Hormonal profile of women of reproductive age investigated for infertility in Bida Metropolis, Niger State, Nigeria.Sch. J. App. Med. Sci; 2017; 5(5A):1750-7. Website

9) Kazemijaliseh H, RamezaniTehrani F. et al.The Prevalence and Causes of Primary Infertility in Iran: A Population-Based Study. Global Journal of Health Science; 2015;7(6),226-32. Crossref

10) Shrivastava VR, Rijal B, Shrestha A, Shrestha HK, Tuladhar AS.Detection of tubal abnormalities by HSG in Nepalese subfertile women. Nepal Med Coll J .2009;11(1):42-5. Website

11) Panti AA, Sununu YT.The profile of infertility in a teaching Hospital in North West Nigeria,Sahel Med J.2014;17: 7-11. Crossref
12) Lawan RO, Ibinaiye PO, Onwuhafua P, Hamidu A. Evaluation of pattern of tubo-peritoneal abnormalities potentially responsible for infertility in Zaria, Nigeria: hysterosalpingographic assessment, SubSaharan Afr J Med .2015;2(3):110-16. Crossref

13) Bukar M, [19] Bukar M, Mustapha Z, Takai UI, Tahir A. Hysterosalpingographic findings in infertile women: A seven-year review, Niger J ClinPract; 2011;14(2): 168-70.

14) Zafar M. Association of body mass index (BMI) and sub-fertility among young women in Karachi, Pakistan. FertilSci Res .2019;6:238. $\underline{\text { Crossref }}$

15) Mokhtar, S,Hassan, H. A, Mahdy, N. ;Elkhwsky , F. and Shehata, G. (2006) . Risk Factors For Primary and Secondary Female Infertility in Alexandria: A Hospital Based Case ControlStudy. JMRI, 27 (4): 255 -61 . Website

16) Ali A. Al-Fahham1, Hisham Q. Al-Nowainy. The role of FSH, LH, and Prolactin Hormones in Female Infertility.Am. J. PharmTech Res. 2016; 6(5). Website

17) Masoumi SZ, Parsa P, Darvish N, Mokhtari S, Yavangi M, Roshanaei G. An epidemiologic survey on the causes of infertility in patients referred to infertility center in Fatemieh Hospital in Hamadan. Iran J Reprod Med. 2015;13(8):513-6. Website

18) Safarinejad MR. Infertility among couples in a population- based study in Iran: prevalence and associated risk factors. Int J Androl. 2008;31(3):303-14. Crossref

19) Patel M, Jain S, Jain D, Patel B, Phanse N, Vyas P, Rathore P. Prevalence of Different Factors Responsible for Infertility . Research Journal of Recent Sciences .2012;1:207-11. Website

20) Ramzan R, Praveen S, Jehan S. Hysterosalpingographic findings among infertile women, Isra Med J. (2015;7(4): 216-19. Crossref

21) Bukar M, Mustapha Z, Takai UI, Tahir A. Hysterosalpingographic findings in infertile women: A seven-year review, Niger J ClinPract.2011;14(2):168-70. Crossref

22) Malwadde EK, Byanyima RK, Structural findings at hysterosalpingography in patients with infertility at two private clinics in Kampala, Afr Health Sci .2004;4(3):178-81. Website 